\title{
Scorpion venoms in gastric cancer (Review)
}

\author{
XIAO-YING ZHANG ${ }^{1}$ and PEI-YING ZHANG ${ }^{2}$ \\ ${ }^{1}$ Nanjing University of Chinese Medicine, Information Institute, Nanjing; ${ }^{2}$ Department of Cardiology, \\ Xuzhou Central Hospital, The Affiliated Xuzhou Hospital of Medical College of Southeast University, \\ Xuzhou, Jiangsu 221009, P.R. China
}

Received April 27, 2016; Accepted September 1, 2016

DOI: $10.3892 / \mathrm{ol} .2016 .5134$

\begin{abstract}
Venom secretions from snakes, scorpions, spiders and bees, have been widely applied in traditional medicine and current biopharmaceutical research. Possession of anticancer potential is another novel discovery for animal venoms and toxins. An increasing number of studies have shown the anticancer effects of venoms and toxins of snakes, and scorpions in vitro and in vivo, which were achieved mainly through the inhibition of cancer growth, arrest of cell cycle, induction of apoptosis and suppression of cancer metastasis. However, more evidence is needed to support this concept and the mechanisms of anticancer actions are not clearly understood. The present review is focused on the recant updates on
\end{abstract} anticancer venom research.

\section{Contents}

1. Introduction

2. Scorpion venoms and toxins

3. NaScTxs from scorpion venom

4. KTxs from scorpion venom

5. $\mathrm{Ca}^{2+}$ and $\mathrm{Cl}^{-}$channel toxins from scorpion venoms

6. Scorpion venom peptides with NDBPs

7. High MW enzymes

8. LAAOs from scorpion and snake venoms

9. The anticancer potential of scorpion venoms and toxins

10. Conclusion

\section{Introduction}

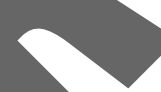

Venom is the secretion of venom glands found in certain snakes, scorpions, spiders, bees, lizards, cone snails and sea

Correspondence to: Dr Pei-Ying Zhang, Department of Cardiology,

Xuzhou Central Hospital, The Affiliated Xuzhou Hospital of Medical College of Southeast University, 199 South Jiefang Road, Xuzhou, Jiangsu 221009, P.R. China

E-mail: xiaoyingzhang08@163.com

Key words: venom, cancer, therapeutics anemones (1). The venoms could be secreted in teeth, stingers, claws or even the skins of these animals, to paralyze and kill the prey or to protect themselves from predation and other dangers. The signs and symptoms after exposure to venoms vary from mild allergic reactions including itch, pain, swelling to respiratory arrest, paralysis, necrosis or even death (2). The utilization of animal venoms in folk medicine has been documented for a long time in some countries, such as China, India and the Middle East. For example, Chan $\mathrm{Su}$, the dried toad venom from skin glands, first recorded in traditional Chinese medicine more than 1,000 years ago, has been long used as a diuretic,cardiøtonic and anesthetic agent (3). Animal venoms are complex cocktails with various bioactive proteins/peptides and are variable between different species, making animal venoms a rich source for drug discovery. For the last 30 years, animal venoms and toxins have been widely investigated in the treatment of human disorders, such as diabetes, hypertension, chronic pain, HIV and cancer (4).

\section{Scorpion venoms and toxins}

Scorpion venoms are a complex mixture of water, salts, mucoproteins, lipids, nucleotides, glycoaminoglycans, histamine, serotonin, biogenic amines, low molecular weight (MW) peptides (e.g., neurotoxins), and high MW proteins (e.g., enzymes) (Fig. 1) (5). Each scorpion species has its own component profile in the venom and the number varies from dozens to hundreds. Small peptides $(<10 \mathrm{kDa})$ are the most important components in scorpion venoms, which are believed to be responsible for intoxication and are widely investigated for biomedical and scientific applications. They are often considered as neurotoxins because the majority of peptides target and modify the ion channels of the excitable cells (e.g., neurons), which makes them valuable tools for ion channel research in neuroscience (5). Based on the types of targeted ion channels, scorpion venom peptides can be classified into four groups: Sodium $\left(\mathrm{Na}^{+}\right)$, potassium $\left(\mathrm{K}^{+}\right)$, calcium $\left(\mathrm{Ca}^{2+}\right)$ and chloride $\left(\mathrm{Cl}^{-}\right)$channel toxins

\section{NaScTxs from scorpion venoms}

$\mathrm{Na}^{+}$-channel scorpion toxins (NaScTxs) are polypeptides of 60-76 amino acid residues in length (6.5-8.5 kDa), tightly bound by four disulfide bridges. Current databases such as ArachnoServer (https://omictools.com/arachnoserver-tool) 


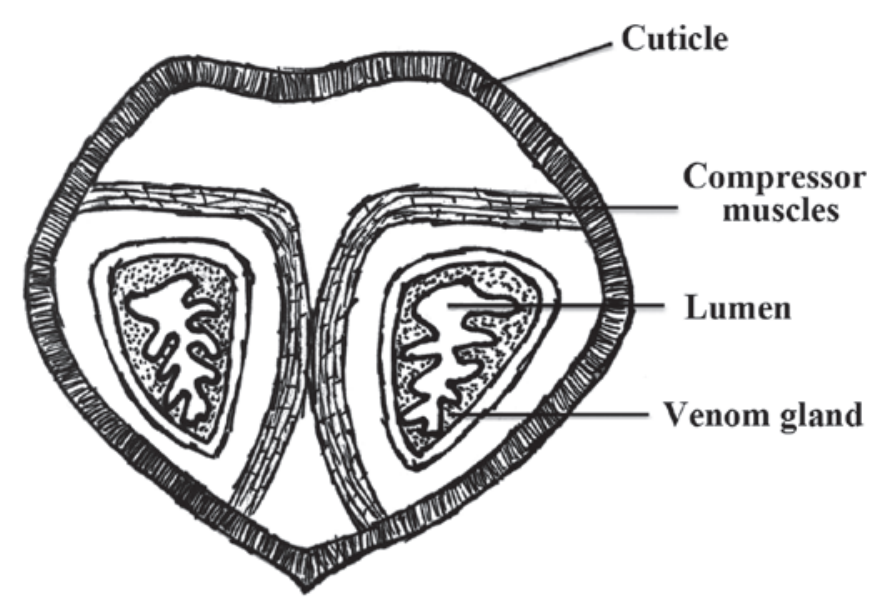

Figure 1. Diagram of scorpion venom glands.

cover approximately 200 sequences of putative NaScTxs (6). The phyletic preference has been reported among NaScTxs, which principally classifies NaScTxs into two groups: 'Classical', highly active on mammalian $\mathrm{Na}^{+}$channels; and 'antiinsect', highly active on insect $\mathrm{Na}^{+}$channels. The latter toxins are subdivided into excitatory and depressant insect toxins (7).

\section{KTxs from scorpion venoms}

Scorpion venoms are rich sources of $\mathrm{K}^{+}$channel toxins which block several types of $\mathrm{K}^{+}$channels, e.g., voltage-gatec $\mathrm{K}^{+}$channels (Kv1.x), and $\mathrm{Ca}^{2+}$ activated $\mathrm{K}^{+}$channels of small, intermediate and high conductance. KTxs are structurally categorized into four families: $\alpha-, \beta-, \gamma$ - and $\kappa-\mathrm{KT}$ Tx, most of which share a conserved cysteine-stabilized $\alpha$-helix and $\beta$-sheet structural motif $(\mathrm{CS} \alpha \beta)(8)$. The $\alpha-\mathrm{KTx}$ family is considered as the largest in number, with approximately 140 peptides falling in 26 subfamilies, termed $\alpha$-KTx $1-26$ and new peptides are described continuously (9). These peptides are composed of 23-42 amino acid residues with 3 or 4 disulfide bridges. These families of toxins are important blockers of $\mathrm{Kv1.x}$ and attract much attention in the studies of Kv channel structure-function and Kv-related channelopathies (10). The $\beta$-KTxs are long-chain peptides with 50-75 amino acid residues. The $\gamma$-KTxs are new interesting short chain peptides mainly targeting hERG channels, which are associated with the cell cycle and proliferation of several cancers (11).

\section{5. $\mathrm{Ca}^{2+}$ and $\mathrm{Cl}^{-}$channel toxins from scorpion venoms}

Different from NaScTxs and KTxs, scorpion venom peptides that target $\mathrm{Ca}^{2+}$ and $\mathrm{Cl}^{-}$channels, are scarcely known and have variable amino acid lengths (12). Imperatoxin A (IpTxa) proteins were purified from Pandinus imperator scorpion venom, and were also identified from other scorpion venoms, including maurocalcin, hemicalcin and hadrucalcin (7). Chlorotoxin (CTX/ClTx), a 36 amino acid small peptide purified from the Leiurus quinquestriatus scorpion venom, was initially described as a $\mathrm{Cl}^{-}$channel blocker that acts as a paralytic agent for small insects (13). A noteworthy finding and application of this toxin is that CTX can specifically bind to the $\mathrm{Cl}^{-}$channel on glioma cells and inhibit glioma progression (14). A phase II clinical trial is in progress with 131I-TM-601, a synthetic CTX coupled with radioactive iodine isotope (15).

\section{Scorpion venom peptides with NDBPs}

In addition to the ion channel-targeted peptides with disulfide bridges, there are a number of non-disulfide-bridged peptides (NDBPs) in scorpion venoms (16). These peptides show high diversity in structure and bioactivities. Currently, more than 40 scorpion venom NDBPs have been isolated and functionally described. The majority of NDBPs are antimicrobial peptides with a board spectrum of activity against bacteria, yeast, fungi and viruses (17). Hadruin, a 41 amino acid peptide isolated from Hadrurus aztecus, was the first to show antimicrobial activities at low micromolar concentrations (10-50 $\mu \mathrm{M})$ (18).Mucroporin-M1, a modified antimicrobial peptide from scorpion Lychas mucronatus, was demonstrated to have antibacterial activity against antibiotic-resistant pathogens (19).

\section{High MW enzymes}

The high MW proteins in scorpion venoms are mainly diverse enzymes, which are believed to contribute to the venom cytotoxicity or potentiate the envenomation process. Therefore, a good understanding of these enzymes' structures and functions is useful for anti-venom strategy. In contrast to spider and snake venoms, scorpion venoms exhibit low levels of enzymatic activities (20). The enzymes present in scorpion venoms include hyaluronidase, phospholipase A2 (PLA2), L-amino acid oxidases (LAAOs) and proteases (21).

Hyaluronidase. Hyaluronidase can be found in several venomous species including snake, bee, spider and scorpion. This enzyme can degrade the hyaluronan, an extracellular matrix protein present in the soft connective tissues around blood vessels and increase the diffusion of toxins (22). Hyaluronidase has been purified from a few scorpion venoms, e.g., Heterometrus fulvipes, Tityus serrulatus and Palamneus gravimanus. BmHYA1, a hyaluronidase isolated from Mesobuthus martensi Karsch (BmK), was shown to remove hyaluronan and modulate the expression of CD44 variant in MDA-MB-231 breast cancer cells (23).

PLA2. PLA2 is a group of enzymes that hydrolyze the ester bonds of phospholipids into lysophospholipid, and fatty acids (24). The PLA2s described in scorpion venoms belong to SPLA2, which have a low MW (13-15 kDa) and are involved in tissue destruction and inflammation during the action of scorpionism (25). These enzymes have diverse biological and pharmacological potentials such as anti-coagulant and antibacterial activities (26).

Proteases. Proteases are important proteins in venoms that are involved in the post-translational processing of toxins and promote the spreading of toxins via degradation of matrix proteins. Two main types of proteases are identified in scorpion venoms: Serine proteases and metalloproteases (27). The first metalloprotease purified from scorpion venom was named antarease from the Brazilian scorpion Tityus serrulatus, which 
cleaves the vesicle-associated membrane proteins 2 and 8 (VAMP2 and VAMP8) (28). A serine protease-like protein (BMK-CBP) was also isolated from the Chinese red scorpion $\mathrm{BmK}(29)$.

\section{LAAOs from scorpion and snake venoms}

LAAOs are a group of flavoenzymes that catalyze oxidative deamination of L-amino acid substrates and form the corresponding $\alpha$-keto acids, hydrogen peroxide and ammonia (30). LAAOs could be widely found in nature, including bacteria, fungi, seaweeds and snake venoms.

The presence of LAAOs in scorpion venoms is not widely reported but its activity is observed in the Chinese red scorpion venom BmK (31). Snake venoms are the richest source of LAAOs, which are responsible for the yellowish colour for the venoms. Recently, LAAOs have become a research interest in biomedicine because they have multieffects including anti-microbial, anti-HIV, anti-coagulant, apoptosis-inducing, edema-inducing and hemorrhagic activities (32). Notably, some snake venom LAAOs can induce platelet aggregation, such as LAAOs from B. moojeni, Bothrops atrox and Trimeresurus jerdonii. While LAAOs from snake venoms of Vipera berus, Naja oxiana and others, were reported to inhibit platelet aggregation. The application of LAAOs in cancer research is another recent scientific attempt, by applying the cytotoxic effects of $\mathrm{H}_{2} \mathrm{O}_{2}$ generated from LAAO enzymatic reaction.

\section{The anticancer potential of scorpion venoms and toxins}

Scorpion envenomation is a risk for public health in tropical and subtropical regions and there is a clear need for the improvement in specific (anti-venom) and systematic treatments. Scorpions and scorpion venoms have been applied in traditional medicine for long perióds in China, India and Africa (33). Additionally, scorpion venoms have antimicrobial functions against bacteria, fungi, yeasts and viruses. Studies showed that scorpion venom-derived protein mucroporin-M1 inhibited the amplification of hepatitis virus B and another peptide Kn2-7 possesses anti-HIV-1 activity (34).

The anticancer potential is another recently observed biological property of scorpion venoms and toxins. A number of experimental and preclinical studies have shown that scorpion venoms and toxins could impair cancer growth, induce apoptosis and inhibit cancer metastasis in vitro and in vivo. Several active molecules with confirmed anticancerous activities such as proliferation inhibition, cell cycle arrest, induction of apoptosis and decreasing cell migration have been purified from scorpion venoms. The investigated cancer types included glioma, neuroblastoma, leukemia, lymphoma, breast, lung and prostate cancers (35).

Among all the scorpions tested in cancer research, the $\mathrm{BmK}$ scorpion venom is probably the first to be reported to possess antitumor properties. BmK scorpion venom is the most extensively studied in China and several active molecules have been isolated and characterized.

Polypeptide extract from the scorpion venom (PESV), a group of partially purified polypeptides with 50-60 amino acids from the crude venom of $\mathrm{BmK}$, was reported to inhibit cell proliferation and induce cell apoptosis of DU 145 human prostate cancer cells (36). An analgesic-antitumor peptide (AGAP) isolated from a fusion protein SUMO-AGAP, which connected a small ubiquitin-related modifier to AGAP, inhibited cell proliferation and migration of SHG-44 human malignant glioma cells via interfering with the $\mathrm{p}-\mathrm{AKT}$, NF- $\mathrm{B}, \mathrm{BCL}-2$, and MAPK signaling pathways (37). The most notable evidence regarding the anticancer effects of scorpion venoms comes from CTX utilized in the treatment of glioma. Based on electrophysiological evidence, the $\mathrm{Cl}^{-}$ channel was initially considered to be responsible for the affinity and specificity of CTX to glioma. However, further studies by protein interaction approaches with a recombinant His-CTX, revealed that the principle receptor of CTX is matrix metalloproteinase-2 (MMP-2), a protease that is overexpressed on the surface

\section{Conclusions}

It can be concluded that scorpion venoms hold great potential in their actions against cancer cells via targeting the ion channels to inhibit cell proliferation and metastasis, secondly via induction of apoptosis by cell cycle arrest, caspase activation,-and mitochondria depolarization or oxidative stress. Nevertheless, as a novel research field, more efforts should be made to extensively evaluate the anticancer effects of scorpion venoms and toxins to understand the mechanisms of action.

\section{References}

1. Zhang L, Chen C, Cao Y, Xie B, Chen X, Zeng F and Liu M: Purification and immunoprotection evaluation of AaHIV from complex venom metalloproteinases of Deinagkistrodon acutus. J Biochem Mol Toxicol: Apr 25, 2016 (Epub ahead of print).

2. Weinstein S, Dart R, Staples A and White J: Envenomations: an overview of clinical toxinology for the primary care physician. Am Fam Physician 80: 793-802, 2009.

3. Meng Z, Yang P, Shen Y, Bei W, Zhang Y, Ge Y, Newman RA, Cohen L, Liu L, Thornton B, et al: Pilot study of huachansu in patients with hepatocellular carcinoma, nonsmall-cell lung cancer, or pancreatic cancer. Cancer 115: 5309-5318, 2009.

4. Lewis RJ and Garcia ML: Therapeutic potential of venom peptides. Nat Rev Drug Discov 2: 790-802, 2003.

5. Andreotti N, Jouirou B, Mouhat S, Mouhat L and Sabatier JM: Therapeutic value of peptides from animal venoms. In: Comprehensive Natural Products II. Mander L and Liu HW (eds). Vol 5. Elsevier, Oxford, pp287-303, 2010.

6. Srinivasan KN, Gopalakrishnakone P, Tan PT, Chew KC, Cheng B, Kini RM, Koh JL, Seah SH and Brusic V: SCORPION, a molecular database of scorpion toxins. Toxicon 40: 23-31, 2002.

7. Quintero-Hernández V, Jiménez-Vargas JM, Gurrola GB, Valdivia HH and Possani LD: Scorpion venom components that affect ion-channels function. Toxicon 76: 328-342, 2013.

8. Rodríguez de la Vega RC and Possani LD: Current views on scorpion toxins specific for $\mathrm{K}^{+}$-channels. Toxicon 43: 865-875, 2004

9. Diego-García E, Peigneur S, Debaveye S, Gheldof E, Tytgat J and Caliskan F: Novel potassium channel blocker venom peptides from Mesobuthus gibbosus (Scorpiones: Buthidae). Toxicon 61: 72-82, 2013.

10. Castle NA: Pharmacological modulation of voltage-gated potassium channels as a therapeutic strategy. Expert Opin Ther Pat 20:1471-1503, 2010.

11. Asher V, Sowter H, Shaw R, Bali A and Khan R: Eag and HERG potassium channels as novel therapeutic targets in cancer. World J Surg Oncol 8: 113, 2010.

12. Possani LD, Merino E, Corona M, Bolivar F and Becerril B: Peptides and genes coding for scorpion toxins that affect ion-channels. Biochimie 82: 861-868, 2000. 
13. DeBin JA, Maggio JE and Strichartz GR: Purification and characterization of chlorotoxin, a chloride channel ligand from the venom of the scorpion. Am J Physiol 264: C361-C369, 1993.

14. Lyons SA, O'Neal J and Sontheimer H: Chlorotoxin, a scorpion-derived peptide, specifically binds to gliomas and tumors of neuroectodermal origin. Glia 39: 162-173, 2002.

15. Mamelak AN, Rosenfeld S, Bucholz R, Raubitschek A, Nabors LB, Fiveash JB, Shen S, Khazaeli MB, Colcher D, Liu A, et al: Phase I single-dose study of intracavitary-administered iodine-131-TM-601 in adults with recurrent high-grade glioma. J Clin Oncol 24: 3644-3650, 2006.

16. Almaaytah A and Albalas Q: Scorpion venom peptides with no disulfide bridges: a review. Peptides 51: 35-45, 2014.

17. Hancock RE and Sahl HG: Antimicrobial and host-defense peptides as new anti-infective therapeutic strategies. Nat Biotechnol 24: 1551-1557, 2006.

18. Torres-Larios A1, Gurrola GB, Zamudio FZ and Possani LD: Hadrurin, a new antimicrobial peptide from the venom of the scorpion Hadrurus aztecus. Eur J Biochem 267: 5023-5025, 2000

19. Dai C, Ma Y, Zhao Z, Zhao R, Wang Q, Wu Y, Cao Z and Li W: Mucroporin, the first cationic host defense peptide from the venom of Lychas mucronatus. Antimicrob Agents Chemother 52 3967-3972, 2008.

20. Gwee MC, Nirthanan S, Khoo HE, Gopalakrishnakone P, Kini RM and Cheah LS: Autonomic effects of some scorpion venoms and toxins. Clin Exp Pharmacol Physiol 29: 795-801, 2002.

21. Petricevich VL: Scorpion venom and the inflammatory response. Mediators Inflamm 2010: 903295, 2010.

22. Girish KS and Kemparaju K: The magic glue hyaluronan and its eraser hyaluronidase: a biological overview. Life Sci 80 : 1921-1943, 2007.

23. Feng L, Gao R and Gopalakrishnakone P: Isolation and characterization of a hyaluronidase from the venom of Chinese red scorpion Buthus martensi. Comp Biochem Physiol C Toxicol Pharmacol 148: 250-257, 2008.

24. Burke JE and Dennis EA: Phospholipase $\mathrm{A}_{2}$ structure/function, mechanism, and signaling. J Lipid Res 50: S237-S242, 2009.

25. Incamnoi P, Patramanon R, Thammasirirak S, Chaveerach Uawonggul N, Sukprasert S, Rungsa P, Daduang J and Daduang S: Heteromtoxin (HmTx), a novel heterodimeric phospholipas A(2) from Heterometrus laoticus scorpion venom. Toxicon 61 62-71, 2013.
26. Perumal Samy R, Gopalakrishnakone P, Thwin MM, Chow TK, Bow H, Yap EH and Thong TW: Antibacterial activity of snake, scorpion and bee venoms: a comparison with purified venom phospholipase $\mathrm{A}_{2}$ enzymes. J Appl Microbiol 102: 650-659, 2007.

27. Valdez-Velázquez LL, Quintero-Hernández V, RomeroGutiérrez MT, Coronas FIV and Possani LD: Mass fingerprinting of the venom and transcriptome of venom gland of scorpion Centruroides tecomanus. PLoS One 8: e66486, 2013.

28. Fletcher PL Jr, Fletcher MD, Weninger K, Anderson TE and Martin BM: Vesicle-associated membrane protein (VAMP) cleavage by a new metalloprotease from the Brazilian scorpion Tityus serrulatus. J Biol Chem 285: 7405-7416, 2010.

29. GaoF,LiH, Chen YD, Yu XN, Wang R and Chen XL: Upregulation of PTEN involved in scorpion venom-induced apoptosis in a lymphoma cell line. Leuk Lymphoma 50: 633-641, 2009.

30. Du XY and Clemetson KJ: Snake venom L-amino acid oxidases. Toxicon 40: 659-665, 2002

31. Ahn MY, Ryu KS, Lee YW and Rim YS: Cytotoxicity and L-amino acid oxidase actiyity of crude insect drugs. Arch Pharm Res 23: 477-481, 2000.

32. Tan NH and Fung SY: Snake venom L-amino acid oxidases and their potential biomedical applications. Malaysian J Biochem Mole Biol 16: 1-10, 2008

33. Shao J, Kang N, Liu Y, Song S, Wu C and Zhang J: Purification and characterization of an analgesic peptide from Buthus martensii Karsch. Biomed Chromatogr 21: 1266-1271, 2007.

34. Chen Y, Cao L, Zhong M, Zhang Y, Han C, Li Q, Yang J, Zhou D, Shi W, He B, et al: Anti-HIV-1 activity of a new scorpion venom peptide derivative Kn2-7.PLoS One 7: e34947, 2012.

35. Ding J, Chua PJ, Bay BH and Gopalakrishnakone P: Scorpion venoms as a potential source of novel cancer therapeutic compounds. Exp Biol Med (Maywood) 239: 387-393, 2014 Zhang J, Yang PL and Gray NS: Targeting cancer with small molecule kinase inhibitors. Nat Rev Cancer 9: 28-39, 2009

37. Zhao Y, Cai X, Ye T, Huo J, Liu C, Zhang S and Cao P: Analgesic-antitumor peptide inhibits proliferation and migration of SHG-44 human malignant glioma cells. J Cell Biochem 112: 2424-2434, 2011.

8. Deshane J, Garner CC and Sontheimer H: Chlorotoxin inhibits glioma cell invasion via matrix metalloproteinase-2. J Biol Chem 278: 4135-4144, 2003. 